\title{
Hospital Management of Children with Acute Asthma Exacerbations in Kuwait: Adherence to International Guidelines
}

\author{
Z. Hijazi ${ }^{a}$ A.K. Abdulmalek ${ }^{b}$ F. Al-Taweel ${ }^{b}$ S. Al-Sharedab \\ aDepartment of Paediatrics, Faculty of Medicine, Kuwait University, and bMubarak Al-Kabeer Hospital, \\ Ministry of Public Health, Kuwait
}

\section{Key Words}

Acute asthma, management . Audit . Kuwait .

Developing country

\begin{abstract}
Objectives: To evaluate the in-patient management of children with acute exacerbation of bronchial asthma and its adherence to international guidelines. Subjects and Methods: Medical records of 100 consecutive admissions for acute exacerbation of asthma to the paediatric wards at Mubarak Al-Kabeer Hospital, Kuwait, from October through December 1999 were retrieved. Data relevant to asthma symptoms, severity, treatment regimens and discharge plan were collected and evaluated. The mean age of patients was 4.3 years, ranging from 2 to 12 years. Admissions totalled 82 males and $18 \mathrm{fe}$ males, with hospital stays ranging from 1 to 11 days (mean $=2.6$ days). Results: There were no fatalities. Reported episodes were severe (17\%), moderate $(11 \%)$ and mild (9\%); degree of severity was not documented in 63 cases. Pulse, respiratory rate, colour and use of accessory muscles were not documented in $48,48,47$ and $63 \%$ of the patients, respectively. Arterial blood gas was checked in 16 patients and pulse oximetry in 71 . Full
\end{abstract}

blood count, serum urea and electrolytes were obtained in 86 patients and chest radiographs in 76. All patients received nebulized salbutamol. However, some received additional medications: ipratropium bromide (79\%), steroids (95\%), intravenous aminophylline (5\%) and antibiotics (43\%). Two children were shifted to an intensive care unit, 1 of whom needed intubation. On discharge, there was no documentation of follow-up arrangements, or prophylactic anti-inflammatory drugs or other medications in 52, 81 and 32 patients, respectively. Conclusion: Patient management showed deficits, and documentation was inadequate. Areas of particular concern were assessment of patients, unnecessary investigations and use of antibiotics, and lack of post-discharge planning and prophylaxis with steroids. Adherence to the international guidelines was partial.

Copyright $($ 2002 S. Karger AG, Basel

\section{Introduction}

Asthma continues to pose a significant medical problem worldwide, in terms of prevalence, morbidity and mortality $[1,2]$. Inadequate management of acute exacerbation carries potential danger to a patient's life [3]. Poor

\begin{tabular}{ll}
\hline KARGER & ( ) 2002 S. Karger AG, Basel \\
Fax +4161306 1234 & 1011-7571/02/0113-0126\$18.50/0 \\
$\begin{array}{l}\text { E-Mail karger@karger.ch } \\
\text { www.karger.com }\end{array}$ & $\begin{array}{l}\text { Accessible online at: } \\
\text { www.karger.com/journals/mpp }\end{array}$
\end{tabular}

Dr. Zeinat Hijazi, Associate Professor

Paediatric Department, Faculty of Medicine

PO Box 24923

13110 Safat (Kuwait)

Tel. +965 5319486, Fax +965 5338940, E-Mail zeinat@hsc.kuniv.edu.kw 
Table 1. Failure of documentation of clinical findings in acute exacerbations of asthma among the 100 admissions

\begin{tabular}{ll}
\hline Item & Not recorded, \% \\
\hline Pulse & 48 \\
Colour & 47 \\
Respiratory rate & 48 \\
Use of accessory muscles & 62 \\
Wheeze & 2 \\
Crepitations & 52 \\
Assessment of attack severity & 63 \\
\hline
\end{tabular}

documentation and management of asthma in hospitals have been reported by several centres [4-6]. Moreover, the medical care received by patients with exacerbations may vary significantly [7]. For these reasons, the international guidelines for the diagnosis and management of asthma [8] were set forth to assist physicians and patients in deciding appropriate acute as well as long-term management.

In Kuwait, a small desert country, bronchial asthma is a growing problem [9], with evidence of an increasing number of children admitted to hospitals for bronchial asthma [10]. The estimated prevalence of asthma among 13- to 14 -year-old children is $16.8 \%$ [11]. In an attempt to improve the care of asthmatic children admitted to $\mathrm{Mu}$ barak Al-Kabeer Hospital, Kuwait, we introduced a standard protocol based on international guidelines [8] in our wards for the treatment of acute exacerbations of bronchial asthma as well as for long-term management. This initial study evaluates the extent of adherence to these guidelines.

\section{Subjects and Methods}

Prior to the implementation of these guidelines, several meetings and discussion sessions were held to educate the medical staff. Special emphasis was placed on the role of steroids in acute as well as chronic asthma. The guidelines were made available on all paediatric wards and the staff was advised to implement them on all patients admitted with asthma. The medical staff was not made aware that evaluation of the standard of care and documentation would be conducted.

Over a period of 3 months (October through December 1999), 100 consecutive patients with acute exacerbations of asthma were admitted to the paediatric wards. Of a total of 100 admissions, 82 were boys and 18 girls. The age of patients ranged from 10 months to 12 years, with a mean age of 3.2 years. Seventy-three patients were
Table 2. Frequency of investigations carried out among the 100 admissions

\begin{tabular}{ll}
\hline Investigation & Performed, \% \\
\hline Pulse oximetry & 71 \\
Arterial blood gas & 16 \\
Complete blood counts & 86 \\
Serum urea and electrolytes & 86 \\
Chest X-ray & 76 \\
Throat swab & 17 \\
PEFR & 13 \\
\hline
\end{tabular}

admitted once only; 12 were admitted more than once $(9$ patients twice and 3 patients 3 times). Their hospital records were retrieved and analysed for the following: data of admission, history of previous asthma, previous hospital admission, medications prior to admission, findings on clinical examination such as pulse, respiratory rate, use of accessory muscles, presence of wheezing, assessment of severity of acute exacerbation, investigations including oxygen saturation, arterial blood gas measurement, chest X-ray, blood count, urea and electrolytes, throat swab and peak expiratory flow rate (PEFR). Details of treatment given including dosage and duration, as well as discharge plan including follow-up arrangement and continued therapy, were noted. The absence of documentation for any of the above was also noted.

\section{Results}

Episodes were reported as severe in 17, moderate in 11 and mild in 9 cases. Degree of severity was not documented in 63 patients. The duration of hospital stay was 1-11 days (mean 2.6 days). Two children were shifted to intensive care. Although 1 needed assisted ventilation, there were no fatalities.

Eighty-seven percent of the patients had a past history of asthma, 3\% had not, while for $10 \%$ this information was not recorded. Equally important, $45 \%$ of the patients had been previously admitted for asthma, $13 \%$ were not and for $15 \%$ no information was recorded. Thirty-six patients received medications previously, 29 did not, and information was missing in 35 cases.

Wheezing was documented in almost all patients, whereas pulse, respiratory rate and colour were not documented in almost $50 \%$ (table 1). The majority of children $(>75 \%)$ were exposed to unnecessary investigations such as chest X-ray and venepuncture, while PEFR was not checked in almost $90 \%$ (table 2). 
Table 3. Frequency of medications administered in acute exacerbation of asthma among the 100 admissions

\begin{tabular}{|c|c|c|c|c|c|c|}
\hline & $\begin{array}{l}\text { Continuous } \\
\text { for } 1-3 \mathrm{~h}\end{array}$ & $\begin{array}{l}\text { Hourly } \\
\text { for } 2-8 \mathrm{~h}\end{array}$ & $\begin{array}{l}\text { 2-hourly } \\
\text { for } 4-8 \mathrm{~h}\end{array}$ & 4-hourly & 6-hourly & Total \\
\hline Salbutamol & 14 & 42 & 25 & 13 & 6 & 100 \\
\hline Ipratropium bromide & 0 & 8 & 9 & 47 & 15 & 79 \\
\hline Hydrocortisone & & & 6 & 22 & 40 & 68 \\
\hline Prednisolone ${ }^{1}$ & & & & & 9 & 9 \\
\hline Aminophylline & & & & & 5 & 5 \\
\hline Antibiotics $^{2}$ & & & & & 32 & 43 \\
\hline
\end{tabular}

Prednisolone was given 8-hourly.

Antibiotics: of 43 patients, 32 received it intravenously (6-hourly) and 11 orally (8-hourly).
For initial treatment, all patients received at least 4 doses of nebulized salbutamol ranging from 0.01 to $0.03 \mathrm{ml} / \mathrm{kg} / \mathrm{dose}$ (or $0.05-0.15 \mathrm{mg} / \mathrm{kg} / \mathrm{dose}$ ), and $79 \% \mathrm{re}-$ ceived additional ipratropium bromide at $125-500 \mu \mathrm{g} /$ dose. Nebulizers, driven by high-flow oxygen, were administered at frequencies shown in table 3 . Steroids were prescribed on 95 occasions for a median duration of 3 days (ranging from 2 to 6 days). Eighty-six patients received the steroids in the form of intravenous hydrocortisone and 9 patients as oral prednisolone. The dose ranged between 3 and $10 \mathrm{mg} / \mathrm{kg} /$ day for hydrocortisone (median $5.5 \mathrm{mg} / \mathrm{kg}$ ) and $1-2 \mathrm{mg} / \mathrm{kg} /$ day prednisolone (median $1.7 \mathrm{mg} / \mathrm{kg}$ ). Intravenous aminophylline was given to 5 patients: all had severe exacerbation of their asthma and 2 needed assisted ventilation. Oxygen via mask was received by 36 patients for a period of 3-28 h (mean 6.5) and antibiotics were prescribed for $43 \%$ of the admissions. Table 4 is a summary of action probably taken but not documented before discharge of these patients.

\section{Discussion}

The use of asthma assessment and management protocols helps overcome many of the clinical problems associated with the management of acute asthma. Their implementation also serves an educational function when used by junior staff members who are usually delegated responsibility for the care of asthmatic children. Results of our study show multiple problems in conforming to the standard care delineated in the standard protocol. In addition, documentation was poor and management ineffective.

The presence of wheezing was the single most recorded observation (98\%). However, essential data such as the
Table 4. Failure of documentation of management plan at discharge among the 100 admissions

\begin{tabular}{ll}
\hline Item & Not documented, \% \\
\hline Follow-up arrangement & 52 \\
Discharge therapy recorded & 32 \\
Prophylactic therapy & 81 \\
Prophylaxis and follow-up & 91 \\
\hline
\end{tabular}

degree of accessory muscle use, pulse, respiratory rate and colour were not recorded in almost $50 \%$ of cases (table 1). PEFR, a simple test bearing directly on the severity of the attack, was not recorded in almost $90 \%$ of the cases, and overall assessment of the severity of attack was not recorded in $63 \%$ of the children. This raises considerable concern as to the basis of a management plan, which is determined by the severity of an attack followed by appropriate therapy as recommended $[8,12]$. Frequent or continuous nebulization of $\beta_{2}$-agonists is required in acute severe asthma as recommended by the recent international guidelines. Eighty percent of our patients received frequent (2-hourly, hourly and continuous) nebulization of $\beta_{2}$-agonists, which suggests that $80 \%$ of episodes were severe as opposed to the $17 \%$ that were recorded. In addition, $79 \%$ received additional ipratropium bromide (table 3), which also suggests that attacks were perceived as severe by admitting staff. In all cases, the actual doses prescribed per nebulization were acceptable on all occasions. The argument that severity could have been assessed and not documented demonstrates inadequate management 
strategy, which could carry additional risk of mismanagement because it failed to provide baseline data necessary for optimizing therapy. In addition, documentation is a mandatory requirement for continuing care by medical personnel working on different shifts and teams.

Antibiotics have no role in treating acute attacks of asthma, being indicated only for patients who also have bacterial infection such as sinusitis or pneumonia [12]. Forty-three percent of our patients received antibiotics, in most cases intravenously and almost all without justification: only 1 patient had associated pneumonia (Mycoplasma pneumoniae) and 2 otitis media. Overprescription of antibiotics is not unusual in this part of the world. A previous study [13] in this hospital showed that the majority of children with viral respiratory tract infections received antibiotics. However, this may be a major problem worldwide.

It has been shown that the incidence of radiographic abnormalities in asthma is low, abnormalities are minor and usually do not substantially influence treatment [14]. In acute asthma, chest X-rays are essentially used to detect complications such as pneumothorax or atelectasis and hardly add anything if routinely performed [15]. In this study, $76 \%$ of children had a chest radiograph performed on admission of whom 23 had previous ones despite the fact that only $17 \%$ were reported as having severe asthmatic episodes. In our hospital, the use of antibiotics and chest X-rays was left to the discretion of the treating doctor. Unnecessary chest $\mathrm{X}$-rays in acute asthma have been reported from developed [14-16] as well as developing countries [17]. This practice indicates unnecessary exposure of children to radiation as well as unnecessary increase in cost.

Salbutamol and steroids may cause hypokalaemia; thus, monitoring of potassium concentration is desirable when these drugs are frequently used as in severe acute exacerbations [18]. The overwhelming majority of our patients had an order for serum urea and electrolytes on admission, rather than after they had received repeated doses of salbutamol and hydrocortisone. Simultaneously, a complete blood count was carried out on the same children. This is not part of recommended guidelines, as complete blood count may only be of some help if concomitant bacterial infection is likely. Likewise, serum potassium should routinely be selectively and appropriately watched for, not routinely administered.

Almost $95 \%$ of patients received corticosteroids during acute attack, consistent with the guidelines [8]. However, our findings showed no adherence to these recommendations as the overwhelming majority of the patients (ta- ble 4) were not on prophylactic anti-inflammatory therapy as recommended in all guidelines [8, 19-21]. Antiinflammatory therapy is important in planning long-term management. Failure of adherence to anti-inflammatory medications for treatment of chronic disease may be responsible in part for continued disease activity.

In this first documentation of the standard of inpatient care of asthmatic children with acute exacerbation in Kuwait, our observations are more negative than others $[4,6]$, but very similar to and slightly better than others [17]. In-hospital treatment with asthma medications was appropriate. However, documentation of assessment of asthma severity was inadequate, patients were unnecessarily exposed to radiation and venepuncture and received unnecessary antibiotics, and planning on discharge was missing and patients were deprived of the benefit of prophylaxis with inhaled steroids.

\section{Conclusion}

The provision of the management guidelines in this hospital has positively influenced the emphasis on acute treatment (increased use of corticosteroids, continuous administration of nebulized salbutamol, and more utilization of pulse oximetry) but not documentation or longterm plans. It is imperative that these aspects of management are addressed and closer compliance reinforced. 


\section{References}

1 Kun HY, Oates RK, Mellis CM: Hospital admissions and attendances for asthma: A true increase? Med J Aust 1993;159:312-313.

2 Arrighi HM: US asthma mortality. Ann Allergy Asthma Immunol 1995;74:321-326.

3 DeNicola LK, Monem GF, O'Gayle M, Kissoon $\mathrm{N}$ : The treatment of critical status asthmaticus in children. Pediatr Clin North Am 1994:41:1293-1324

4 Teo S, Hanson R, Van Asperen P, Giles H, Fasher B, Davis AM, Kristidis P: Improving asthma documentation in paediatric emergency department. J Paediatr Child Health 1995; 31:130-133.

5 Canny GJ, Reisman J, Healy R, Schwartz C, Petrou C, Rebucks AS, Levinson $\mathrm{H}$ : Acute asthma: Observations regarding the management of a pediatric emergency room. Pediatrics 1989;83:507-512.

6 Dawson KP, Penna AC: Observations of the management of childhood acute asthma in a large hospital. Med J Aust 1992;156:845-846.

7 Crain EF, Weiss KB, Fagan MJ: Pediatric asthma care in US emergency departments: Current practice in the context of the National Institutes of Health Guidelines. Arch Pediatr Adolesc Med 1995;149:893-901.
8 Global Initiative for Asthma: Global Strategy for Asthma Management and Prevention: NHLBI/WHO Workshop Report. National Institute of Health, Publication 95-3659. National Heart, Lung, and Blood Institute, 1995.

9 Ellul-Micallef R, Al-Ali S: The spectrum of bronchial asthma in Kuwait. Clin Allergy 1984; 14:509-517.

10 Strannegard IL, Strannegard O: Childhood asthma in a desert country. Allergy 1990;45: 327-333.

11 Worldwide variation in prevalence of symptoms of asthma, allergic rhinoconjunctivitis, and atopic eczema: ISAAC. The International Study of Asthma and Allergies in Childhood. Lancet 1998;351:1225-1232.

12 Downey P, Cox R: Update on the management of status asthmaticus. Curr Opin Pediatr 1996; 8:226-233.

13 Hijazi Z, Pacsa A, El-Gharbawy F, Chugh T, Essa S, El-Shazli A, El-Salam R: Acute lower respiratory tract infections in children in $\mathrm{Ku}-$ wait. Ann Trop Paediatr 1997;17:127-134.

14 Brooks LJ, Cloutier MM, Afshani E: Significance of roentgenographic abnormalities in children hospitalized for asthma. Chest 1982; 82:315-318.

15 Dawson KP, Capaldi N: The chest X-ray and childhood acute asthma. Aust Clin Rev 1993; 13:153-156.
16 Daley J, Kopelman RI, Comeau E, Ginns LC, Rossing TH: Practice patterns in the treatment of acutely ill hospitalized asthmatic patients at three teaching hospitals: Variability in resource utilization. Chest 1991;100:51-56.

17 Dawson KP, Aithala GR: How are acute asthma episodes managed and documented in a rapidly developing country? Emirates Med J 1999; 17:151-153.

18 Singhi SC, Jayashree K, Sarkar B: Hypokalaemia following nebulized salbutamol in children with acute attack of bronchial asthma. J Paediatr Child Health 1996;32:495-497.

19 British Thoracic Society Guidelines. Thorax 1997;52(suppl):S1-2.

20 National Heart, Blood and Lung Institute: National Asthma Education and Prevention Program. Expert panel report 2. Guidelines for the diagnosis and management of asthma. NIH Publication 97-4051. Bethesda, US Department of Health and Human Services, 1997, p 20.

21 Global Initiative for Asthma: NHLBI/WHO Pocket Guide for Asthma Management and Prevention. National Institute of Health, Publication 96-3659B. National Heart, Lung, and Blood Institute, 1998. 